\title{
Quality assessment and antioxidant study of Pleurotus djamor (Rumph. ex Fr.) Boedijn
}

\author{
Krishnendu Acharya*, Somanjana Khatua, Saswata Ray \\ Molecular and Applied Mycology and Plant Pathology Laboratory, Centre of Advanced Study, Department of Botany, University of Calcutta, 35, \\ Ballygunge Circular Road, Kolkata- 700019, West Bengal, India.
}

\begin{tabular}{l} 
ARTICLE INFO \\
\hline Article history: \\
Received on: $23 / 01 / 2017$ \\
Accepted on: $20 / 03 / 2017$ \\
Available online: $30 / 06 / 2017$ \\
\hline Key words: \\
Antioxidant property, HPLC, \\
Medicinal mushroom, \\
Pharmacognostic \\
standardization, Physico- \\
chemical evaluation.
\end{tabular}

\begin{abstract}
Pleurotus djamor is an important oyster mushroom that has attracted much attention due to its high nutritional value and diverse therapeutic properties. However, quality standards of this species remain unexplored so far. For this purpose, microscopic features of powder such as physical characters, spore measurement, type of hyphae were examined and described. Physico-chemical parameters like organoleptic features and fluorescent behaviour against 16 reagents were also determined. In addition, an alcoholic extract was prepared using methanol as solvent to characterize the mushroom chemically and biologically. Preliminary mycochemical analysis indicated presence of major bioactive components in the following order of phenol> ascorbic acid> flavonoid $>\beta$-carotene> lycopene. To determine phenolic fingerprint of the extract, an HPLC profile was recorded. The chromatogram indicated existence of at least nine phenolic components in the extract. Moreover, antioxidant activity of the macrofungus was also evaluated using in vitro assays like DPPH radical scavenging activity $\left(\mathrm{EC}_{50}\right.$ value $0.653 \mathrm{mg} / \mathrm{ml}$ ) and total antioxidant capacity $(16.67 \mu \mathrm{g}$ AAE/mg of extract). In summary, the data as described in this study are significant towards future identification and authentication of genuine mushroom material establishing the pharmacognostic standards. Furthermore, results of antioxidant study indicate that the mature fruiting bodies could be valuable for defending radical induced ailments.
\end{abstract}

\section{INTRODUCTION}

Pharmacognosy is considered as one of the oldest modern science and derived from two Greek words namely "pharmakon" (drug) and "gnosis" (knowledge). About 200 years ago, this subject area was introduced for the study of products and crude drugs of natural origin to authenticate such drugs. Over the course of history, pharmacognosy has expanded considerably beyond traditional techniques such as macroscopic and microscopic identification due to advancement in screening methods. In recent years, it includes study of ethnomedicine, ethnopharmacology, phytochemical analysis, isolation of active principles and more recently, the investigation of biological activity (Sarkar 2012; Jones et al., 2006; Orhan et al., 2014).

\footnotetext{
* Corresponding Author

Email: krish_paper@yahoo.com
}

For maintaining biological processes, oxidation is essential for production of energy in many living organisms. However, gradually the mechanism of oxidation becomes unbalanced, as a result free radicals are produced causing cancer, rheumatoid arthritis, atherosclerosis etc. (Valko et al., 2007). Antioxidants can scavenge free radicals and could be used to help human body from oxidative damage. Several commercial synthetic antioxidants are available in market which are widely used in food industry such as butylatedhyroxyanisole (BHA), butylatedhydroxytoluene (BHT), and tert-butylhydroquinone (TBHQ). Though, these synthetic antioxidants have been restricted for use due to their toxicity and carcinogenicity effects to liver. Therefore, investigation and production of effective natural antioxidants is necessary to reduce oxidative damage without any interference (Khatua et al., 2013; Ahmad et al., 2014). Mushrooms have been used as therapeutic aid for centuries and recently have gained popularity as they are scientifically proved to be a source of physiological beneficial medicine. 
Recent studies have established multi-purpose application of several mushrooms including Astraeus hygrometricus (Pers.) Morgan (Mallick et al., 2015); Entoloma lividoalbum (Kühner \& Romagn.) Kubička (Maity et al., 2014; Maity et al., 2015); Lentinula edodes (Berk.) Pegler (Acharya et al., 2015); Pleurotus flabellatus Sacc. (Dasgupta et al., 2014); Pleurotus florida (Mont.) Singer (Saha et al., 2013); Pleurotus ostreatus (Jacq.) P. Kumm. (Mitra et al., 2013); Pleurotus sajorcaju (Fr.) Singer (Giri et al., 2012); Ramaria aurea (Schaeff.) Quél. (Khatua et al., 2015); Macrocybe crassa (Sacc.) Pegler \& Lodge (Acharya et al., 2015); Russula albonigra (Krombh.) Fr. (Dasgupta et al., 2014); Russula senceis S. Imai (Khatua et al., 2015); Termitomyces clypeatus R. Heim (Pattanayak et al., 2015); Termitomyces eurrhizus (Berk.) R. Heim (Chatterjee et al., 2013); Termitomyces medius R. Heim \& Grassé (Mitra et al., 2014) etc. However it has been noticed that many investigations have been conducted on highly nutritious Pleurotus mushrooms confirming their medicinal importance (Khan et al., 2012). One such popular oyster mushroom is Pleurotus djamor (Rumph. ex Fr.) Boedijn that is recognized worldwide as food which in turn have encouraged for artificial cultivation contributing high economic importance. Researchers are interested with this species as it possesses phytochemical constituents similar with some mushrooms that are already proved to be medicinal such as $P$. florida, P. ostreatus, P. sajor-caju and P. pulmonarious (Guo et al., 2007; Suseem et al., 2011). In earlier experimental studies, $P$. djamor has been found to possess strong analgesic, antiinflammatory and antipyretic activity. Crude extracts of the macrofungus has also exhibited significant in vitro free radical scavenging property, antimicrobial and antiplatelet potentiality (Susem et al., 2013). However literature survey revealed that its quality assessment study is still lacking. Hence, the present work was conducted to evaluate the pharmacognostic parameters and chemical analysis of $P$. djamor collected from West Bengal, India, with a view to establish standards for its identity, quality, purity and molecular composition. In addition, antioxidant activity of the macrofungus was also investigated for future application.

\section{MATERIALS AND METHODS}

\section{Collection}

Basidiocarps of $P$. djamor were collected from Narendrapur Ramkrishna Mission Mushroom Cultivation Unit. A representative specimen (Accession no: CUH AM032) was deposited at CUH herbarium following the method of Pradhan et al., (2015). For powder analysis basidiocarps were dried properly by a field drier at $40^{\circ} \mathrm{C}$ for 1 day to make them crispy. Dried fruit bodies were pulverized using an electric blender, sieved through 160 mesh and stored in an air tight container.

\section{Microscopic evaluation of powdered basidiocarps}

Powdered sample was hydrated and macerated with $10 \%$ $\mathrm{KOH}$ and mounted on glass slide with glycerol. For effective results various stains (Congo red, Melzer's reagent) were used to distinguish different cellular structure. Photomicrographs were taken using compound binocular microscope having sensor aided digital camera and computer attachment (Leica DMLS). Different organoleptic characters like colour, odour, taste, nature of powdered samples were evaluated.

\section{Fluorescence analysis}

Fluorescence analysis was determined using standard Pharmacopoeial method (2007). A small quantity of dried sieved mushroom powder was placed on a grease free clean microscopic slide and 1-2 drop of freshly prepared reagent solutions were added, mixed and waited for 1-2 minutes. The slide was further placed inside the UV chamber and viewed under daylight, short $(254 \mathrm{~nm})$ and long $(365 \mathrm{~nm}) \mathrm{UV}$ radiations. The colour observed by application of different reagents in different radiations were recorded.

\section{Preparation of methanol extract}

Dried powdered fruiting bodies $(5 \mathrm{~g})$ were extracted by stirring with $100 \mathrm{ml}$ of methanol for overnight and subsequently separated by Whatman filter paper. The residue was then reextracted with $30 \mathrm{ml}$ of methanol and the combined methanolic extracts were evaporated at $40^{\circ} \mathrm{C}$ (Rotavapor R3 Büchi, Switzerland) to reduce volume. The methanolic fraction was stored at $-20^{\circ} \mathrm{C}$ in dark bottle until analysis, for no more than 1 month. Percentage yield and organoleptic parameters of the extract were recorded.

\section{Quantitative estimation of myco-chemicals}

The content of total phenolic compounds in extract was estimated using Folin-Ciocalteu reagent and gallic acid as standard. The results were expressed as $\mu \mathrm{g}$ of gallic acid equivalents per mg of dry extract (Singleton et al., 1965). Total flavonoid content was determined using aluminium nitrate and potassium acetate. Quercetin $(5-20 \mu \mathrm{g})$ was used to calculate the standard curve. The results were expressed as $\mu \mathrm{g}$ of quercetin equivalents per mg of dry extract (Park et al., 1997). $\beta$-carotene and lycopene were estimated by measuring absorbance at 453, 505 and $663 \mathrm{~nm}$ (Nagata and Yamashita 1992). Ascorbic acid was determined by titration against 2, 6-dichlorophenol indophenol dye (Rekha et al., 2012).

\section{High performance thin layer chromatography (HPLC) fingerprinting}

The extract was filtered through $0.2 \mu \mathrm{m}$ filter paper and $20 \mu \mathrm{l}$ filtrate was loaded on HPLC system (Agilent, USA). Separation was achieved on an Agilent Eclipse Plus C18 column $(100 \mathrm{~mm} \times 4.6 \mathrm{~mm}, 3.5 \mu \mathrm{m})$ using a flow rate of $0.8 \mathrm{ml} / \mathrm{min}$ at $25^{\circ} \mathrm{C}$. The mobile phase consisted of eluent A (acetonitrile) and eluent B (aqueous phosphoric acid solution, $0.1 \% \mathrm{v} / \mathrm{v}$ ). A gradient program was used for elution: 0-2 $\mathrm{min}, 5 \% \mathrm{~A} ; 2-5 \mathrm{~min}, 15 \% \mathrm{~A} ; 5-$ $10 \mathrm{~min}, 40 \% \mathrm{~A} ; 10-15 \mathrm{~min}, 60 \% \mathrm{~A} ; 15-18 \mathrm{~min}, 90 \% \mathrm{~A}$. The absorbance of sample solution was measured at $280 \mathrm{~nm}$ (Khatua et al., 2015). 


\section{DPPH radical scavenging assay}

Hydrogen atom or electron donation abilities of the methanol extract and a pure compound, ascorbic acid, were measured by bleaching of purple coloured methanol solution of DPPH radical. Various concentrations of extract $(0.5,1$ and 1.5 $\mathrm{mg} / \mathrm{ml}$ ) were added to $2 \mathrm{ml}$ of $0.004 \%$ methanol solution of DPPH $(\mathrm{w} / \mathrm{v})$. After $30 \mathrm{~min}$ incubation period at room temperature in dark, the absorbance was read against a methanol blank at $517 \mathrm{~nm}$ (Shimada et al., 1992). $\mathrm{EC}_{50}$ value is the effective concentration at which DPPH radicals were scavenged by $50 \%$. Degree of scavenging was calculated by the following equation:

$$
\text { Scavenging effect }(\%)=\{(\mathrm{A} 0-\mathrm{A} 1) / \mathrm{A} 0\} \times 100
$$

Where $A_{0}$ and $A_{1}$ were the absorbance of control and absorbance in presence of sample respectively.

\section{Determination of total antioxidant capacity by phosphomolybdenum method}

The assay was carried out as described by Prieto et al., (1999) with little modification. The reaction mixture consisted of $0.3 \mathrm{ml}$ sample solution and $3 \mathrm{ml}$ of reagent solution $(0.6 \mathrm{M}$ sulphuric acid, $28 \mathrm{mM}$ sodium sulphate and $4 \mathrm{mM}$ ammonium molybdate). Blank was prepared by adding $0.3 \mathrm{ml}$ water and $3 \mathrm{ml}$ reagent solution. Tubes were capped and incubated at $95^{\circ} \mathrm{C}$ for 90 min. samples were cooled at room temperature and absorbance was measured at $695 \mathrm{~nm}$ against blank. Concentrations of ascorbic acid $(1-30 \mu \mathrm{g})$ were used to obtain a standard curve. Total antioxidant activity was expressed as the number of ascorbic acid equivalents (AAE).

\section{RESULTS AND DISCUSSION}

After passing through sieve, the dried powder appeared yellowish-brown coloured, pungent in smell, tasteless and granular in texture (Figure 1). After maceration with $\mathrm{HNO}_{3}$ and $\mathrm{KOH}$ separately, micro-morphological observations revealed the following characters: basidiospores (7.87-)8.28-11.18(-12.43) $\times$ (3.73-)4.14-4.97(-5.38) $\mu \mathrm{m}$, oblong, hyaline, inamyloid, thik walled with suprahillar depression; basidia 20.71-21.12 × 4.14$4.56 \mu \mathrm{m}$, narrowly clavate, tetrasterigmatic sterigmata 3.31-3.73 $\times$ $0.41 \mu \mathrm{m}$; pleurocystidia absent; rostrate to lecithiform cystidium like element cystidiole present, 25.78-29.4 × 3.73-5.73 $\mu \mathrm{m}$; hyphal system dimitic, generative hyphae hyaline to yellowish brown, thin to thick-walled; skeletal hyphae blackish, thin walled; clamp connection present.

Fluorescence is the property of some atoms and molecules to absorb light at a particular wavelength and subsequently emit light of longer wavelength. It is an important parameter for pharmacognostic evaluation by which crude drugs are often assessed qualitatively. The crude drug may consisted of various chemical constituents that exhibit fluorescence in UV light. However, the non-fluorescent compounds often can be converted to fluorescent compounds by applying different reagents. As a result fluorescence analysis displayed an array of colours that could be employed for identification of authentic samples and recognize adulterates (Sonibare et al., 2015;
Bhattacharya et al., 2009). In the present study powder drug was treated with 16 different chemical reagents which gave characteristic colour when observed under UV light $(254 \mathrm{~nm}, 365 \mathrm{~nm})$ and was compared with colour detected under visible light (Table 1).

It has been reported that most of the components in mushroom fruiting bodies have high polarity $(\mathrm{Wu}$ and Hansen 2008). In the present study, methanol was chosen for preparation of a fraction where the formulation appeared yellow in colour. The extract was subjected for quantitative analysis of different myochemicals using standard protocol. The fraction was found to contain phenol as much as $7.845 \pm 1.22 \mu \mathrm{g}$ gallic acid equivalent/mg of dry extract. Total flavonoid content was determined by using quercetin as standard. The extract contained flavonoid as $2.876 \pm 0.893 \mu \mathrm{g}$ quercetin equivalent $/ \mathrm{mg}$ of extract. Very negligible amount of $\beta$-carotene and lycopene were found such as $0.045 \pm 0.006 \mu \mathrm{g} / \mathrm{mg}$ and $0.033 \pm 0.002 \mu \mathrm{g} / \mathrm{mg}$ of the extract respectively. Ascorbic acid was found in the higher amount i.e. $6.94 \pm 1.389 \mu \mathrm{g} / \mathrm{mg}$ of extract.

HPLC is an efficient and valuable technology for the preliminary separation and determination of constituents. Figure 2 represents HPLC fingerprint profile of the methanol extract which was found to be consisting of at least nine phenols (Rt $4.583 \mathrm{~min}$, area 10.145; Rt 5.044 min, area 299.758; Rt $5.14 \mathrm{~min}$, area 410.51; Rt 5.685 min, area 42.835; Rt $6.37 \mathrm{~min}$, area 62.236; Rt $9.997 \mathrm{~min}$, area 10.14 397.012; Rt $10.733 \mathrm{~min}$, area 55.696; Rt $11.009 \mathrm{~min}$, area 71.672; Rt $15.972 \mathrm{~min}$, area 227.292).

To assess the antioxidant capacity of an extract, DPPH radicals are most often used as they are extremely stable and easy to use. It is a stable $\mathrm{N}_{2}$-centered free radical which accepts an electron/hydrogen to gain stability. In methanol solution DPPH radical produces violet colour which is changed to yellow, depending on capacity of the antioxidant tested. The solution loses colour depending upon the number of electron taken up and colour change is determined by decrease in its absorbance at $517 \mathrm{~nm}$ (Dash et al., 2005; Waltasinghe and Shahidi 1999). DPPH radical scavenging activity of the methanol extract from $P$. djamor was directly correlated with the concentration of the sample (Figure 3 ). The extract exhibited radical scavenging activity at the rate of $33.33 \%, 87.84 \%$ and $95.58 \%$ at $0.5,1$ and $1.5 \mathrm{mg} / \mathrm{ml}$ concentrations respectively. $\mathrm{EC}_{50}$ value was found to be at $0.653 \pm$ $0.156 \mathrm{mg} / \mathrm{ml}$ which was much higher than that of ascorbic acid, a positive control, $(0.004 \mathrm{mg} / \mathrm{ml})$. Recently Jeena et al (Jeena et al., 2014) have reported the DPPH radical scavenging activity of methanolic extract from three oyster mushrooms viz. P. ostreatus, $P$. sapidus and $P$. sajor-caju. Results showed that the lowest $\mathrm{EC}_{50}$ value was at $2 \mathrm{mg} / \mathrm{ml}$ concentration represented by $P$. sajor-caju which was much higher than that of $P$. djamor. Phosphomolybdenum method is a good technique for evaluation of total antioxidant capacity. The method is based on reduction of Mo (VI) to Mo (V) by the antioxidant compound and the formation of green phosphate/Mo (V) complex at acidic $\mathrm{pH}$. Total antioxidant capacity of the fraction was investigated and compared against ascorbic acid. The extract presented $16.67 \pm 2.66 \mu \mathrm{g}$ AAE/ mg of extract total antioxidant activity. 
Table 1: Fluorescence analysis of dry powder from Pleurotus djamor.

\begin{tabular}{|c|c|c|c|c|}
\hline \multirow[t]{2}{*}{ SI No. } & \multirow[t]{2}{*}{ Reagent } & \multirow[t]{2}{*}{ Visible } & \multicolumn{2}{|c|}{$\mathbf{U V}$} \\
\hline & & & Long (365nm) & Short (254nm) \\
\hline 1 & Powder as such & Whitish yellow & Deep brown & Whitish brown \\
\hline 2 & Hager's & Lemon yellow & Dark golden brown & Butter yellow to maize yellow \\
\hline 3 & Mayer's & Birch bark to flesh & Greyish violet & Creamish yellow \\
\hline 4 & Dragendroff's & Reddish orange & Persian red to cuba & Light brown \\
\hline 5 & Iodine solution & Reddish brown & Purplish brown & Dark brown \\
\hline 6 & $1(\mathrm{~N}) \mathrm{HNO}_{3}$ & Light cream & Light brown & Creamish yellow \\
\hline 7 & $50 \% \mathrm{HNO}_{3}$ & Reddish green & Brownish green & Light brownish green \\
\hline 8 & Phloroglucinol & Light yellow & Violet brown & Sap green \\
\hline 9 & Barfoed & Olive green & Brownish black & Greyish brown \\
\hline 10 & Sodium nitroprusside & Creamish yellow & Reddish brown & Sap green \\
\hline 11 & $\mathrm{H}_{2} \mathrm{O}$ & Whitish yellow & Deep brown & Light yellow \\
\hline 12 & $\mathrm{FeCl}_{3}$ & Light brown & Deep brown & Sap green \\
\hline 13 & $1(\mathrm{~N}) \mathrm{NaOH}$ & Greyish orange & Dark golden brown & Greenish brown \\
\hline 14 & Acetic acid & Straw & Greyish brown & Light yellow to greenish yellow \\
\hline 15 & $1(\mathrm{~N}) \mathrm{HCl}$ & Greenish yellow & Brownish grey & Greyish yellow \\
\hline 16 & Methanol & Creamish orange & Dark brownish red & Creamish green \\
\hline 17 & $1(\mathrm{~N}) \mathrm{NaOH}$ in methanol & Greyish orange & Dark golden brown & Greenish brown \\
\hline
\end{tabular}

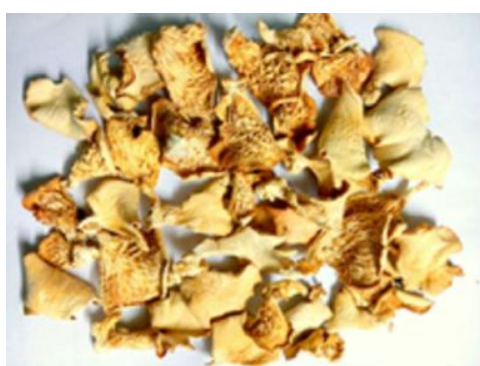

A

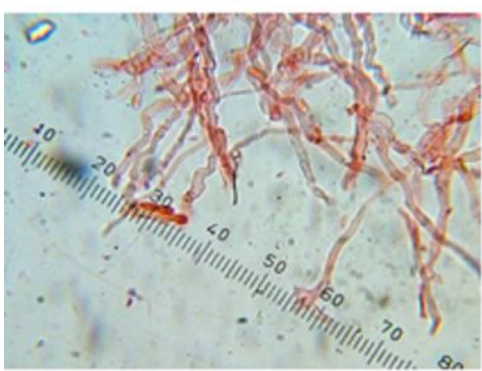

D

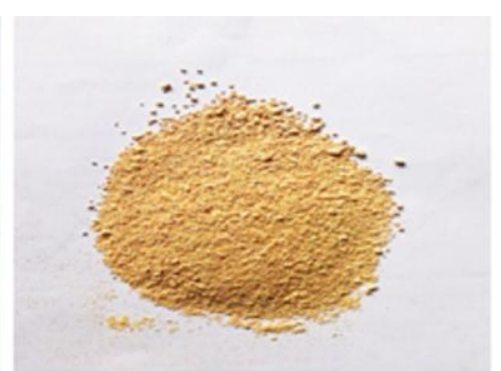

B

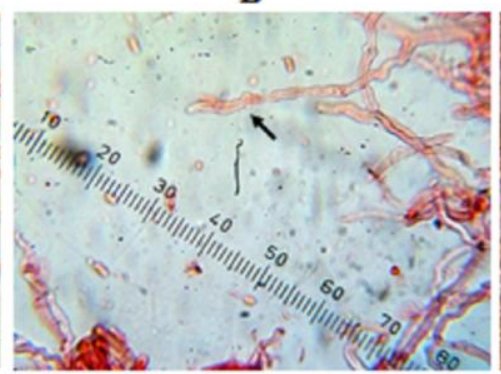

$\mathbf{E}$

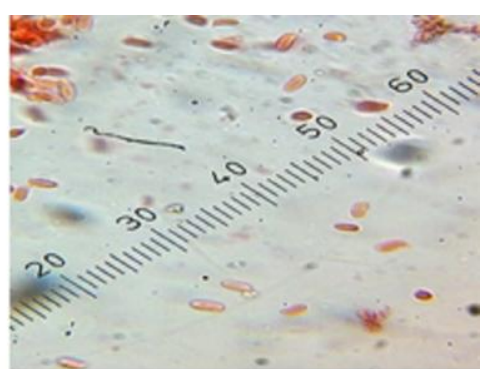

C

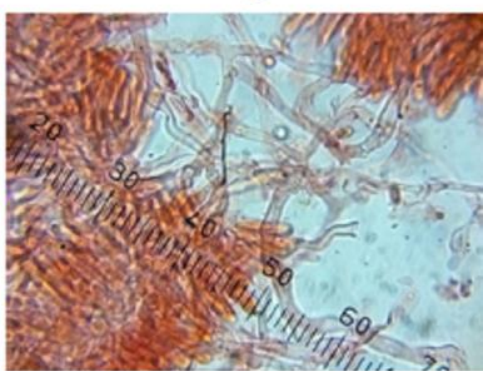

$\mathbf{F}$

Fig. 1: Macroscopic and microscopic characters of Pleurotus djamor.

A: Dried basidiocarps B: Fruit body in powder form B: Spores D-F: Types of hyphae (arrow indicates clamp connection).

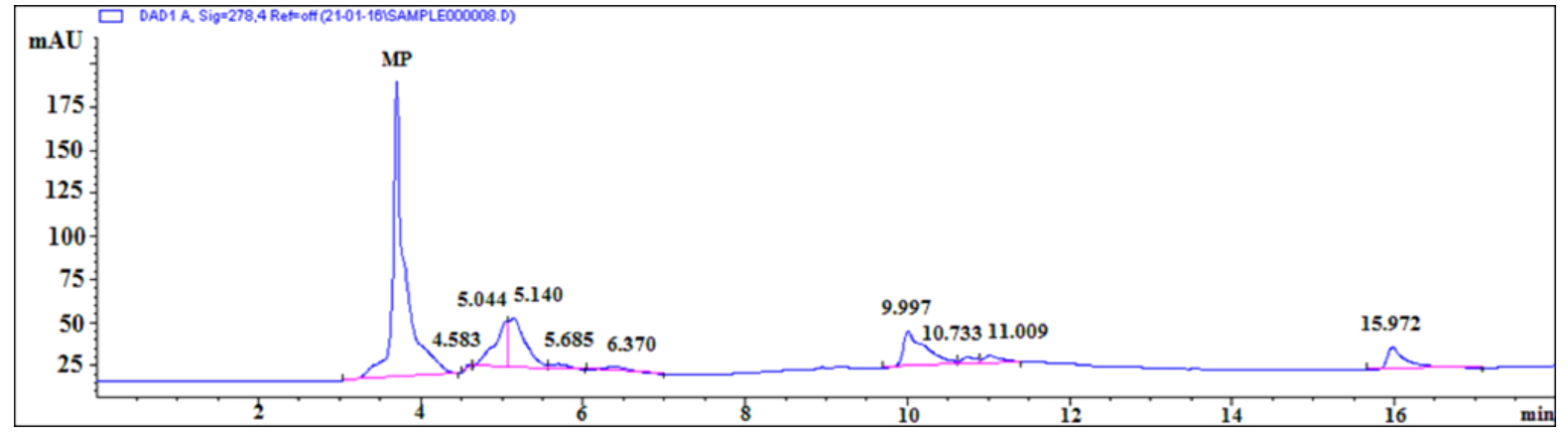

Fig. 2: Enlarged HPLC chromatogram of methanol extract from Pleurotus djamor (MP: Mobile phase). 


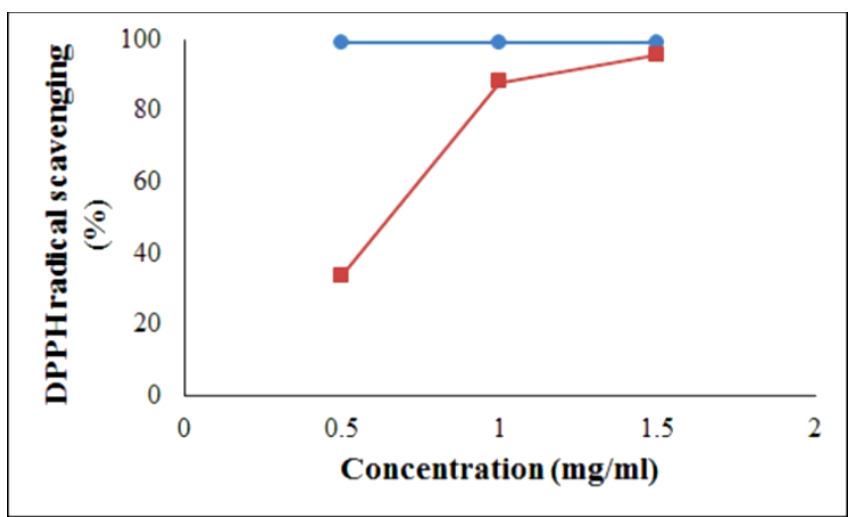

Fig. 3: DPPH radical scavenging activity of methanol extract from Pleurotus djamor.

\section{CONCLUSION}

The present work provides information for correct identification and standardization of $P$. djamor powder with help of modern techniques and suitable parameters. For quality control studies microscopic features, physico-chemical constants, mycochemical investigation and HPLC profile were evaluated which would be helpful for establishing the pharmacopeia standards. Moreover, antioxidant activity of methanol extract from the mushroom was also investigated. The macrofungus exhibited high DPPH radical inhibitory action and total antioxidant capacity. Thus this study provides information concerning pharmacognosy and bioactivity of $P$. djamor which may be useful for authentication and development of nutraceuticals respectively.

\section{Financial support and sponsorship: Nil.}

Conflict of interests: There are no conflicts of interest.

\section{REFERENCES}

Acharya K, Khatua S, Sahid S. Pharmacognostic standardization of Macrocybe crassa: an imminent medicinal mushroom, Res J Pharm Technol, 2015; 8(7):860-866.

Acharya K, Mukherjee S, Mitra P. Pharmacognostic standardisation of Lentinula edodes: A widely explored medicinal mushroom, Int J Pharmacogn Phytochem Res, 2015; 7(4): 866-872 .

Ahmad R, Muniandy S, Shukri NIA, Alias SMU, Hamid AA, Yusoff WMW et al. Antioxidant properties and glucan compositions of various crude extract from Lentinus squarrosulus mycelial culture, Adv Biosci Biotechnol, 2014; 5:805-814.

Bhattacharya S, Zaman MK. Pharmacognostical evaluation of Zanthoxylum nitidum bark, Int J PharmTech Res, 2009; 1(2):292-298.

Chatterjee A, Khatua S, Chatterjee S, Paloi S, Mukherjee S, Mukherjee A et al. Polysaccharide-rich fraction of Termitomyces eurhizus accelerate healing of indomethacin induced gastric ulcer in mice, Glycoconjugate J, 2013; 30:759-768.

Dasgupta A, Ray D, Chatterjee A, Roy A, Acharya K. Antioxidative effect of polyphenol-rich extract of Russula albonigra, Res J Pharm Biol Chem Sci, 2014; 5(1):510-520.

Dasgupta A, Sherpa AR, Acharya K. Phytochemical screening and antioxidant capacity of polyphenol rich fraction of Pleurotus flabellatus, J Chem Pharm Res, 2014; 6(5):1059-1065.
Dash S, Nath LK, Bhise S, Bhuyan N. Antioxidant and antimicrobial activities of Heracleum nepalense D Don root, Trop J Pharm Res, 2005; 4:341-347.

Giri S, Biswas G, Mandal SC, Acharya, K. Studies on pharmacognostic profiles of three medicinally important wild edible mushrooms, Int J PharmTech Res, 2012; 4(4):1595-1600.

Guo L, Lin J, Lin J. Non-volatile components of several novel species of edible fungi in China, Food Chem, 2007; 100:643-649.

Indian Pharmacopoeia Commission: Indian Pharmacopoeia. Vol. I. Government of India, New Delhi. 2007.

Jeena GS, Punetha H, Prakash O, Chandra M, Kushwaha KPS. Study on in vitro antioxidant potential of some cultivated Pleurotus species (Oyster mushroom), Indian J Nat Prod Res, 2014; 5(1):56-61.

Jones WP, Young-Won C, Kinghorn AD. The role of pharmacognosy in modern medicine and pharmacy, Curr Drug Targets, 2006; 7(3),247-264.

Khan MD. A, Tania M. Nutritional and Medicinal Importance of Pleurotus Mushrooms: An Overview, Food Rev Int, 2012; 28:313-329.

Khatua S, Dutta AK, Acharya K. Prospecting Russula senecis: A delicacy among the tribes of West Bengal, PeerJ, 2015; 3:e810.

Khatua S, Mitra P, Chandra S, Acharya K. In vitro protective ability of Ramaria aurea against free radical and identification of main phenolic acids by HPLC, J Herbs Spices Med Plants, 2015; 21(4):380-391.

Khatua S, Paul S, Acharya K. Mushroom as the potential source of new generation of antioxidant: a review, Res J Pharm Technol, 2013; 6(5);496-505.

Maity P, Nandi AK, Sen IK, Pattanayak M, Chattopadhyay S, Dash SK et al. Heteroglycan of an edible mushroom Entoloma lividoalbum: Structural characterization and study of its protective role for human lymphocytes, Carbohydr Polym, 2014; 114:157-165.

Maity P, Sen IK, Maji PK, Paloi S, Devi KSP, Acharya K et al. Structural, immunological, and antioxidant studies of $\beta$-glucan from edible mushroom Entoloma lividoalbum, Carbohydr Polym, 2015; 123:350-358.

Mallick S, Dey S, Mandal S, Dutta A, Mukherjee D, Biswas G et al. A novel triterpene from Astraeus hygrometricus induces reactive oxygen species leading to death in Leishmania donovani, Future Microbiol, 2015; 10(5):763-789.

Mitra P, Khatua S, Acharya K. Free radical scavenging and NOS activation properties of water soluble crude polysaccharide from Pleurotus ostreatus, Asian J Pharm Clin Res, 2013; 6(3):67-70.

Mitra P, Sarkar J, Mandal NC, Acharya K. Phytochemical analysis and evaluation of antioxidant efficacy of ethanolic extract of Termitomyces medius, Int J Pharm Sci Rev Res, 2014; 27(2):261-266.

Nagata M, Yamashita I. Simple method for simultaneous determination of chlorophyll and carotenoids in tomato fruit, Nippon Shokuhin Kogyo Gakkaishi, 1992; 39:925-928.

Orhan IE. Pharmacognosy: Science of natural products in drug discovery, BioImpacts, 2014; 4(3),109-110.

Park YK, Koo MH, Ikegaki M, Contado JL. Comparison of the flavonoid aglycone contents of Apis mellifera propolis from various regions of Brazil, Arq Biol Tecnol, 1997; 40:97-106.

Pattanayak M, Samanta S, Maity P, Sen IK, Nandi AK, Manna DK et al. Heteroglycan of an edible mushroom Termitomyces clypeatus: Structure elucidation and antioxidant properties, Carbohydr Res, 2015; 413:30-36

Pradhan P, Dutta AK, Acharya K. A low cost long term preservation of macromycetes for fungarium, Protocol Exchange, 2015; DOI:10.1038/protex.2015.026

Prieto P, Pineda M, Aguilar M. Spectrophotometric quantitation of antioxidant capacity through the formation of phosphomolybdenum complex: specific application to the determination of vitamin E, Anal Biochem, 1999; 269:337-334.

Rekha C, Poornima G, Manasa M, Abhipsa V, Pavithra DJ, Vijay KHT et al. Ascorbic acid, total phenol content and antioxidant activity of fresh juices of four ripe and unripe citrus fruits, Chem Sci Trans, 2012; 1:303-310.

Saha S, Khatua S, Paloi S, Acharya K. Antioxidant and nitric oxide synthase activation properties of water soluble polysaccharides from Pleurotus florida, Int J Green Pharm, 2013; 7(3):182-188. 
Sarker SD. Pharmacognosy in modern pharmacy curricula, Pharmacogn Mag, 2012; 8(30):91-92.

Shimada K, Fujikawa K, Yahara K, Nakamura T. Antioxidative properties of Xanthan on the autoxidation of soybean oil in cyclodextrin emulsion, J Agric Food Chem, 1992; 40:945-948.

Singleton VL, Rossi JrJA. Colorimetry of total phenolics with phosphomolybdio-phosphotungstic acid reagents, Am J Enol Viticult, $1965 ; 16: 144-158$.

Sonibare MA, Olatubosun OV. Pharmacognostic and free radical scavenging evaluation of Cyathula prostate (BI ume) L, Pharmacogn J, 2015; 7(2):107-116.

Suseem SR, Saral MA, Reddy NP, Gregory M. Evaluation of the analgesic activity of ethyl acetate, methanol and aqueous extracts of Pleurotus eous mushroom, Asian Pacific J Trop Med, 2011; 4(2):117-120.

Suseem SR, Saral MA. Analysis on essential fatty acid esters of mushroom Pleurotus eous and its antibacterial activity, Asian J Pharm Clin Res, 2013; 6(1):188-191.

Valko M, Leibfritz D, Moncol J, Cronin MT, Mazur M, Telser $\mathrm{J}$. Free radicals and antioxidants in normal physiological functions and human disease, Int J Biochem Cell Biol, 2007; 39:44-84.

Waltasinghe M, Shahidi F. Antioxidant and free radical scavenging properties of ethanolic extracts of defatted borage (Berapa officinalis L.) seeds, Food Chem, 1999; 63:399-414.

$\mathrm{Wu}$ XJ, Hansen C. Antioxidant capacity, phenolic content, and polysaccharide content of Lentinus edodes grown in whey permeate-based submerged culture, J Food Sci, 2008; 73(1):M1-M8.

\section{How to cite this article:}

Acharya K, Khatua S, Ray S. Quality assessment and antioxidant study of Pleurotus djamor (Rumph. ex Fr.) Boedijn. J App Pharm Sci, 2017; 7 (06): 105-110. 